\title{
Rapid Reversal of Ergotamine-induced Vasospasm
}

\author{
P. Jeffrey Lewis, Thomas W. Noseworthy, Avril A. Fitzgerald, \\ George C. Andrews and Albert J. Geeraert
}

\begin{abstract}
Peripheral ischemia, secondary to ergotamine tartrate and caffeine suppositories is reported in a 48-year-old female. Lower extremity pre-gangrenous changes were unresponsive to surgical sympathectomy, calcium channel blockade, intra-arterial vasodilators and systemic anticoagulation. A dramatic clinical and radiological reversal of the vasospasm was obtained with intravenous sodium nitroprusside when surgical amputation appeared inevitable.
\end{abstract}

RÉSUMÉ: Abolition rapide d'un vasospasme induit par l'ergotamine Nous rapportons la présence d'une ischémie périphérique, secondaire à l'emploi de tartrate d'ergotamine et de suppositoires à la caféine, se produisant chez une femme de 48 ans. Le modifications pré-grangrèneuses des membres inférieurs s'avérèrent résistantes à la sympathectomie chirurgicale, au bloc du transport du calcium, aux vasodilatateurs intra-artériels et à l'anticoagulation systémique. Au moment où l'amputation semblait inévitable, nous avons observé un renversement spectaculaire, clinique et radiologique, du vasospasme, grâce à l'emploi intraveineux du nitroprussiate de sodium.

Can. J. Neurol. Sci. 1986; 13:72-74

Of all the agents used and studied for the treatment of an acute migrainous attack, ergotamine tartrate is reported to be the most effective and widely used. ${ }^{1}$ Ergotamine overdose ${ }^{2}$ or unusual sensitivity ${ }^{3}$ may result in vasospasm with ischemic peripheral arterial manifestations. There is no consistently effective method for the treatment of severe ischemia due to ergotamine intoxication. ${ }^{2}$ This report illustrates a case of ergotamine intoxication producing severe peripheral ischemia unresponsive to medical and surgical therapy. A dramatic reversal of the pre-gangrenous manifestations was rapidly obtained with intravenous sodium nitroprusside (SNP).

\section{CASE REPORT}

A 48-year-old female was admitted to the emergency department complaining of a 2 month history of claudication in her lower limbs. This progressed to rest pain and severe ischemic changes below her knees and in her feet, worse on the right. Shortly before the onset of her symptoms, she began therapy with ergotamine tartrate suppositories for migraine headache. She had a 24 year history of migraine for which she had been treated with a variety of analgesics but never ergotamine compounds. Eight suppositories containing $1.5 \mathrm{mg}$ ergotamine and 160 $\mathrm{mg}$ caffeine were taken over the 2 month period.

There was no previous history of cardiac, peripheral vascular or connective tissue disease. The patient had never experienced Raynaud's phenomenon, was a nonsmoker and was not taking other medications. The admission blood pressure was $120 / 80 \mathrm{~mm} \mathrm{Hg}$, heart rate $90 / \mathrm{min}$ and regular, and a temperature of $37.2^{\circ} \mathrm{C}$. All peripheral vessels in her neck and upper extremities were of normal volume and amplitude. The femoral pulses were weakly palpable but below the knees both lower limbs were cold, pulseless and cyanotic, more pronounced on the right. Rest pain was evident and there was exquisite tenderness to light touch of the right lower leg. There was no voluntary movement of the right foot, the patient could not dorsiflex on command and sensation was absent in the digits. Sensory and motor function was preserved on the left though the limb was cool, pale and pulseless.

A translumbar aortogram was performed on the day of admission (Figure la). This showed a smooth narrowing of the aorta from $20 \mathrm{~mm}$ diameter at the celiac axis to $12 \mathrm{~mm}$ diameter below the renal arteries. There was progressive narrowing of the iliac vessels distally to the superficial and profunda femoral arteries which were tiny and threadlike. The distal superficial femoral artery on the right appeared occluded. Fine narrow collateral vessels were seen in the inguinal and the popliteal regions but no definite vessels were demonstrated distally.

Clinical presentation and history did not suggest vasculitis associated with a connective tissue disease. Furthermore, the erythrocyte sedimentation rate was 10 (Wintrobe). There was a negative rheumatoid latex factor and antinuclear antibody titre, with normal complement levels. A right gastrocnemius muscle biopsy was interpreted as normal and aortic arch, renal and mesenteric angiography demonstrated normal vessels.

Over the next 7 days there was slight improvement in the left foot with evidence of increased warmth and less cyanosis. No improvement

From the Departments of Adult Intensive Care. Medicine. Diagnostic Imaging and Surgery, Royal Alexandra Hospital and the Faculty of Medicine. University of Alberta, Edmonton, Alberta, Canada

Received July 30, 1985. Accepted October 10, 1985

Reprint requests to: Dr. Thomas Noseworthy, Royal Alexandra Hospital, 10240 Kingsway Avenue, Room 4228, Edmonton, Alberta. Canada T5H 3V9 

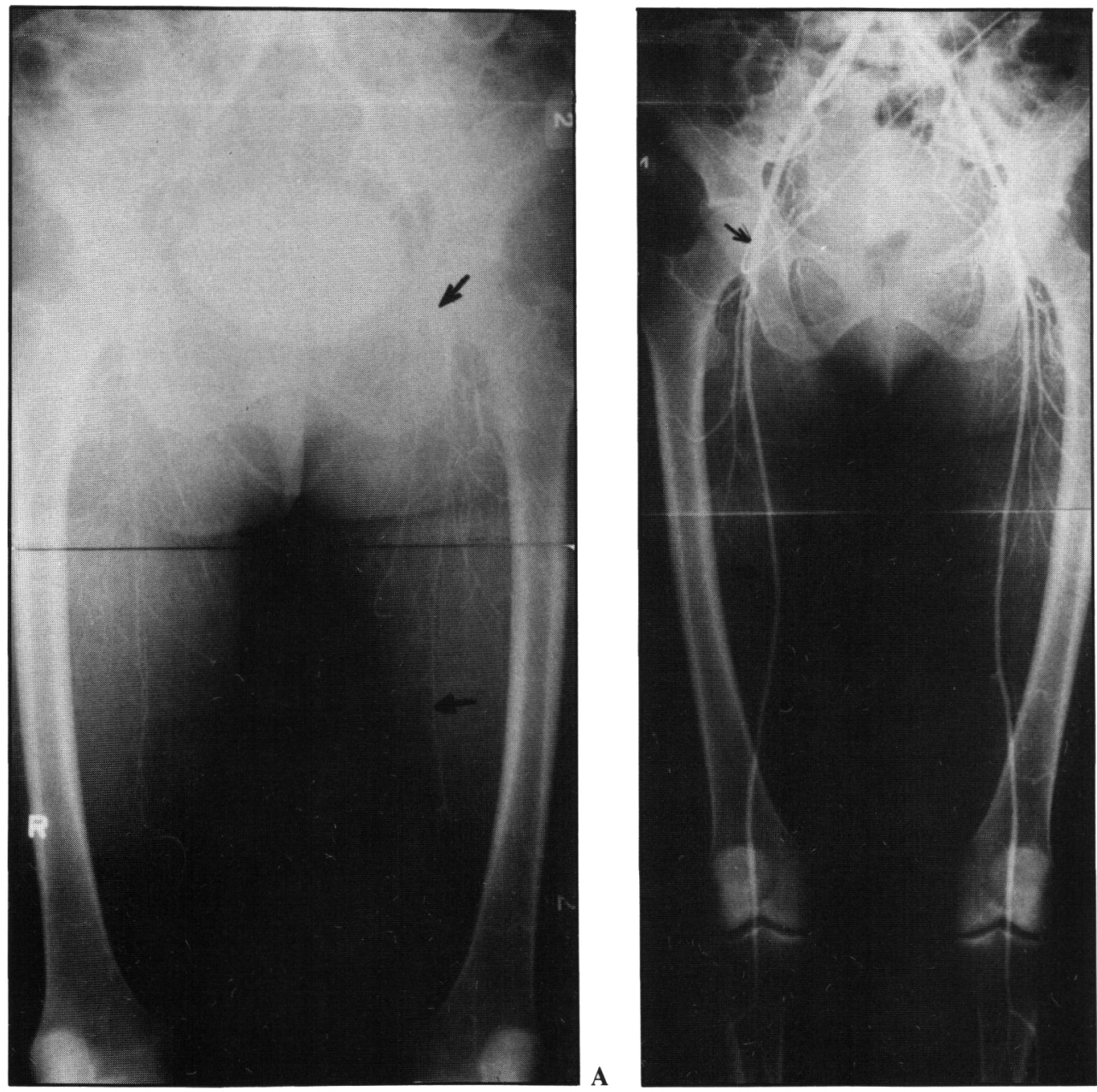

Figure IA - Angiogram showing smooth narrowing of the aorta with progressive narrowing of the iliac vessels distally to the superficial (lower arrow) and profundus femoral arteries, which are tiny and threadlike. (Upper arrow' shows common femoral artery - left). No distal vessels are demonstrated below the knees.

Figure IB - Follow-up angiogram showing normal opacification of the abdomi. nal aorta, iliac femoral, popliteal and tibial vessels.

occurred in the right foot despite discontinuation of ergotamine. Rising creatine phosphokinase (CPK) levels up to $7,000 \mathrm{U} / \mathrm{L}(\mathrm{N}<110 \mathrm{U} / \mathrm{L})$ suggested muscle necrosis. Right lumbar surgical sympathectomy was performed, oral nifedipine $10 \mathrm{mg}$ PO every $8 \mathrm{~h}$ and systemic anticoagulation with heparin was begun. This did not appear to change the vascular supply to the right leg over the succeeding 2 days.

The patient was subsequently admitted to the Intensive Care Unit for 48 hours of intra-arterial papaverine $(2.5 \mathrm{mg} /$ hour $)$ via a 22 gauge polyurethane right femoral artery catheter. Because this did not improve the clinical status, 2 intra-arterial injections of reserpine $1.25 \mathrm{mg}$ were administered 12 hours apart. The CPK level was documented at 15,000 $\mathrm{U} / \mathrm{L}$ at this time. A right above-knee amputation seemed inevitable when an intravenous infusion of sodium nitroprusside (SNP), 0.25 $\mathrm{ug} / \mathrm{kg} / \mathrm{minute}$, was initiated. Within 30 minutes of starting the infusion, an improvement in the vascular supply to both lower limbs was evident with less tenderness and relief of rest pain.

The SNP infusion was increased to $0.5 \mathrm{ug} / \mathrm{kg} /$ minute and a repeat distal aortic angiogram suggested an improvement in circulation. Within 3 hours there was complete resolution of peripheral cyanosis and both feet were warm and painless. Dorsalis pedis and posterior tibial pulses became palpable bilaterally. Twenty-four hours later there was a reversal of the ischemic sensory and motor neuropathy. The SNP was discontinued after a 48 hour infusion.

Follow-up angiography (Figure $1 \mathrm{~b}$ ) performed 2 weeks post-SNP infusion showed marked improvement in the caliber of lower limb vessels with normal opacification of the distal abdominal aorta, iliac, femoral, popliteal, tibial and pedal vessels. The superficial femoral artery in the initial angiogram measured $1 \mathrm{~mm}$ in diameter and $4 \mathrm{~mm}$ on the follow-up angiogram corrected for magnification. The patient was discharged 1 month later, ambulatory with normal peripheral circulation and minimal residual sensory and motor neurological dysfunction of the right foot.

\section{Discussion}

Ergotamine tartrate is one of the most effective agents for aborting acute migrainous attacks. Its direct peripheral vasoconstrictive action restores the dilated scalp vessels to a normal nonpainful state. When combined with caffeine the vasoconstrictor effect is potentiated ' by a synergistic action and there is a faster more complete intestinal absorption of ergotamine. The mechanisms of peripheral vasoconstriction induced by ergotamine are poorly understood, and include direct stimulation of vascular smooth muscle cells. Ergotamine is a partial agonist and antagonist of alpha-adrenergic and tryptaminergic receptors in vascular smooth muscle. Additionally, it is an antagonist of central and peripheral alpha-adrenergic receptors. ${ }^{4}$ The complex response of ergotamine-induced peripheral vasoconstriction may be conceivably altered by a variety of mechanisms which utilize specific receptor subtypes.

The recommended rectal dose is one-half to 1 suppository (1-2 mg ergotamine and 50-100 mg of caffeine) at the onset of a headache, repeated in 1 hour if necessary. Ergotamine administration should not exceed a few times a week with a total weekly dose not greater than $10 \mathrm{mg}$.'

Severe vasospasm resulting in gangrene rarely occurs. Less than $0.01 \%$ of patients taking ergotamine experience this response. ${ }^{2}$ Although ergotamine-induced vasospasm is usually due to overdose, toxic reactions may result from an innate sensitivity to small doses as reported by Fedotin. ${ }^{3}$ 
The temporal relationship between ergotamine consumption and the onset of ischemic manifestations with objective angiographic evidence of large and small vessel vasoconstriction is striking. This patient may have exhibited an innate sensitivity to ergotamine in view of the small total dose taken (12 $\mathrm{mg}$ ) over the 2 month period.

The treatment of ergotamine-induced vasospasm has been inadequate and varied results have been obtained with sympathectomy, intravenous or intra-arterial vasodilators (papaverine, reserpine, hydralazine) or anticoagulation with systemic heparinization. ${ }^{5}$ Merhoff and Porter $^{2}$ suggest that there is no convincing evidence that any treatment other than discontinuation of ergotamine is of benefit in the treatment of ergotism.

This patient obtained mild improvement in her left foot following cessation of ergotamine administration. However, the right foot showed evidence of progressive ischemia despite discontinuation of ergotamine, surgical and medical therapy.

Few other papers ${ }^{5.6}$ have reported near-gangrene from severe ergotamine intoxication and rapid reversal of the ischemic state with SNP. This patient's improvement with SNP was most dramatic in view of a CPK value which peaked at $15,000 \mathrm{U} / \mathrm{L}$ when amputation seemed inevitable.

SNP, a potent direct-acting vasodilator seems particularly suitable for ergotamine-induced vasospasm in view of its direct action on vascular smooth muscle. Though the drug has no known direct antagonistic effect upon ergotamine, its rapid onset and cessation of action allow precise titration of dose.

Intra-arterial infusions ${ }^{6}$ have been shown to be as effective as intravenous administration. If intra-arterial infusions are effective, smaller doses of SNP may avoid hypotensive side-effects. However, the generalized vasodilatory effect of an intravenous infusion would likely be more effective in the face of widespread ergotamine-induced vasospasm and a hypotensive effect from a small dose such as $0.5 \mathrm{ug} / \mathrm{kg} /$ minute can usually be offset by intravenous fluid administration.

Although rare, severe ischemic complications from ergotamine may result in extensive amputations and death. The rapid and dramatic reversal of ergotamine-induced VSP obtained with SNP in this patient should be noted by neurologists, vascular surgeons and other medical personnel likely to encounter this entity.

\section{ACKNOWLEDGEMENTS}

We wish to thank Mrs. Sylvia Goruk for assistance in preparing this manuscript.

\section{REFERENCES}

1. Friedman AP. Headache. In: Baker AB, Baker LH, eds. Clinical Neurology, Vol 2. Hagerton MD: Harper and Row, 1983: 17-19.

2. Merhoff GC, Porter JM. Ergot intoxication: historical review and description of unusual clinical manifestations. Ann Surg 1974; 180: 773-778.

3. Fedotin MS, Hartman C. Ergotamine poisoning producing renal arterial spasm. N Eng J Med 1970; 283: 518-519.

4. Rall TW, Schleifer LS. Oxytocin, prostaglandins, ergot alkaloids, and other agents. In: Gilman AG, Goodman LS, Gilman A, eds. The Pharmacological Basis of Therapeutics, Sixth Edition. New York: MacMillan Publishing Co., Inc., 1980: 939-947.

5. Carliner NH, Denune DP, Finch CS et al. Sodium nitroprusside treatment of ergotamine-induced peripheral ischemia. JAMA 1974; 227: 308-309.

6. Whitsett TL. Nitroprusside reversal of ergotamine-induced ischemia. Am Heart J 1978; 96: 700. 